\title{
Seminário e método entre historiadores que visitaram a Alemanha (1877 - 1909)
}

\section{Seminar and Methods among Historians who Visited Germany (1877 - 1909)}

\author{
Itamar Freitas de OLIVEIRA \\ Departamento de História \\ Universidade de Brasilia \\ Campus Universitário Darci Ribeiro, Brasília, DF, 70.910-900, Brasil \\ itamaroliveiraunb@gmail.com
}

RESUmo Este artigo analisa os discursos de quatro historiadores visitantes da Alemanha, no período 1877-1909, que produziram relatórios de suas excursões a universidades de diferentes estados alemães: Paul Fredericq, da Bélgica, Charles Seignobos, da França, Herbert Baxter Adams, dos Estados Unidos e Ernesto Quesada, da Argentina. Nele discutimos os significados de seminário e método motivados pela literatura sobre a identidade profissional que apresenta os dois objetos como determinantes no processo de formação de uma comunidade transnacional de historiadores na passagem do século XIX para o XX. Examinadas as fontes, concluímos que o multifacetado espaço de produção dos estados germânicos, os interesses individuais, as demandas governamentais e os contextos intelectuais, em termos de ensino superior em história, desencadearam as mais diferentes representações sobre seminário, embora os autores tenham mantido um corpo mínimo de princípios e procedimentos que reforça a ideia de que uma espécie de transnacionalização ocorreu no referido período.

Palavras-Chave seminário, método, Alemanha, ensino superior de história

Recebido: 29 out. 2016 | Revisto pelo autor: 13 jan. 2017 | Aceito: 9 fev. 2017 http://dx.doi.org/10.1590/0104-87752017000200009

Varia Historia, Belo Horizonte, vol. 33, n. 62, p. 491-521, mai/ago 2017 
Abstract This paper analyses the discourse of four historians who visited Germany from 1877 to1909 and produced reports of their tours of universities of different German states: the Belgian Paul Fredericq, the French Charles Seignobos, the North American Herbert Baxter Adams and the Argentine Ernesto Quesada. The article discusses the meanings of seminar and method motivated by the literature on professional identity that presents the two factors as determinants in the formation of a transnational community of historians in the late nineteenth and early twentieth centuries. Through the examination of sources, it concludes that the multifaceted area of production of the German states, individual interests, governmental demands and intellectual contexts, in terms of higher education in history, triggered widely different representations of seminar, although the authors maintained a minimal body of common principles and procedures which reinforces the idea that a kind of trans-nationalization occurred in that period.

KEYWORDS seminary, method, Germany, higher education in history

As palavras "Übung", "historische Uebungen", "Seminar", "historical seminary", "pratice seminar" "séminaire", "seminário histórico" "historischen methode", "critical method", "source method", "méthode critique" são empregadas por muitos historiadores da historiografia de síntese - sobre a Europa, o ocidente e o Globo - para descrever um conjunto de princípios e práticas e até uma instituição que, junto à produção e circulação de manuais sobre o método, criação de cursos de licenciatura, cursos de pós-graduação, associações e revistas especializadas em história ajudariam a explicar o fenômeno "profissionalização do 
historiador" - obviamente, relacionado ao processo de transnacionalização ${ }^{1}$ do método, no período $1860-1930 .^{2}$

Não há consenso sobre a ideia de "profissionalização", tampouco sobre os aportes para explicá-la, sobre os lugares espaciais ou os seus respectivos condicionantes e constituintes. Mas as expressões "seminário" e "método" são constantemente associadas à experiência educacional de Estados alemães, na passagem do século XVIII para o XIX. No Brasil, por exemplo, seminário e as generalistas expressões "problematização", "investigação", "fontes", "crítica" e interpretação" - que nomeariam práticas constitutivas dos seminários, ou seja, dos ambientes de aprendizagem do "método crítico" ou do "método histórico" - até mesmo de modo irrefletido, são associadas a uma espécie de mito de origem ou um utópico horizonte de expectativas, referentes à identidade profissional historiadora, cujo produto mais significativo, ao final do século passado, seria a formação do "professor-pesquisador" em cursos de licenciatura. A repetição ad aeternum ou a ritualização da fala para a manutenção do mito ou da expectativa deixou de ser desejo e foi transformada em verdade epistemológica nos últimos 20 anos (Oliveira, 2015).

Neste texto, também mobilizados por esses desconfortos, investigamos os sentidos das palavras "seminário" e "método" (quando interno ao seminário), transferidas por quatro historiadores não alemães às suas comunidades de origem, na passagem do século XIX ao XX: Charles Seignobos, Herbert Baxter Adams, Paul Fredericq e Ernesto Quesada.

1 Para Thorstendahl, a identidade profissional do historiador emerge em várias partes do mundo, mediada pela aceitação de "minimum demands", ensinadas nos seminários de L. Ranke e por seus discípulos, codificadas em manuais de introdução à história, partilhadas transnacionalmente, em congressos internacionais, sobretudo por europeus e estadunidenses, na primeira metade do século XX, THORSTENDAHL, 2015. Assis, por seu turno, afirma que a elaboração de manuais contribuiu para a formação da ideia de autonomia profissional entre os historiadores e a criação de uma comunidade acadêmica internacional, ASSIS, 2015. Por fim, para Gabriele Ingelbach, que se resume ao espaço europeu, mas escreve especificamente sobre o tema, afirma que o modo de ensino "seminário" foi "particulary effective in ensuring that students were initiated into methodological standards and to the academic habitus" (INGELBACH, 2010, p.24).

2 Essas teses estão disseminadas, principalmente, em obras dos seguintes autores: BREISACH, 1994; BURKE, 2008; FUCHS, 2002; HARRISON; JONES; LAMBERT, 2011; IGGERS, 1997; LE GOFF, 1992; PAUL, 2012; WOOLF, 2014; THORSTENDAHL, 2015. 
Algumas das perguntas que nos norteiam foram claramente anunciadas por Melvin Richter em seus estudos sobre tradução de conceitos políticos entre sociedades europeias e a sociedade chinesa (Richter, 2007): o que ocorre quando determinados autores tentam traduzir conceitos básicos para outras línguas? Há consenso sobre o sentido do conceito -objeto na língua matriz? O autor-tradutor compreende em parte esse sentido? Compreende-o equivocadamente? Acrescenta sentidos encomiásticos? Acrescenta sentidos pejorativos? Que intensões mobilizam esses autores no ato da produção desses novos sentidos?

Essas questões são respondidas a partir do exame de quatro relatórios produzidos entre 1877 e 1910, na Argentina, Bélgica, Estados Unidos, e França, países que enviaram "missões" ou "missionários" à Alemanha para conhecer a organização das instituições de nível superior e, principalmente, os novos métodos de ensino aplicados pela mais inovadora e notória experiência universitária do final do século XIX.

Visando dar cabo à empreitada, lançamos mão de algumas estratégias consagradas no exame de léxicos da historiografia, tradicionalmente originárias da hermenêutica, linguística textual, lexicometria e análise do discurso: (1) apresentação da pergunta histórica; (2) definição do corpus; (3) definição da unidade de análise; (4) leitura e compreensão primária de cada peça documental, visando responder à pergunta que identifica o "todo" - "De que trata o texto?"; (5) leitura, identificação, captura e lematização da unidade de análise; (6) análise estatística e análise semântica de cada relatório; (7) comparação entre os resultados estatísticos e semânticos de cada relatório. ${ }^{3}$

A análise das estratégias de "comunicação intercultural" - a tradução dos conceitos de seminário e método, efetivada pelos citados missionários - é aqui apresentada em cinco tópicos, além das considerações finais. Eles referem-se, respectivamente às "hipóteses sobre a emergência dos seminários de história nos Estados alemães” (tópico 1)

3 Os resultados foram examinados sob perspectiva entrelaçada ou entrecruzada. HAUPT; KOCKA, 2009, posição 500 . 
e aos significados de seminário e método em relatórios produzidos nas línguas francesa (2 e 3), inglesa (4) e espanhola (5).

\section{Hipóteses SOBRe A EMERGÊNCIA DOS SEMINÁRIOS DE HISTÓRIA NA ALEMANHA}

A relevância do seminário histórico - e seminário como instituição da moderna universidade - é um quase-consenso entre os historiadores da historiografia que se ocupam, tangencial ou verticalmente da profissionalidade historiadora. Um dos primeiros estudos sobre o tema e que relaciona seminário à profissionalização foi produzido pelo nova-iorquino Edward Gaylor Bourne (1860-1908). ${ }^{4}$ Ele estabelece o lugar de Ranke na invenção do "método" e os prováveis formadores do citado na promoção dos historische Uebungen [exercícios históricos]: Christian Daniel Beck (1757-1832) e Johann Gottfried Jakob Hermann (1772-1848) (Bourne, 1901, p.265). Bourne também alerta para o valor do trabalho anterior de Johann Christoph Gatterer (1727-1799) e do seu Historisches Institut (Göttingen - 1764), na codificação das citadas práticas. ${ }^{5}$

Em outro texto seminal (1913) o historiador austríaco Wilhelm Erben (1864-1933) apresenta designações mais complexas de modo ideal-típico: seria o seminário tanto um método de ensino quanto uma espécie de instituição não necessariamente edificada em pedra e cal, destinada à formação de professores da escolarização primária e secundária (Clark, 2006, posição 7882). O curioso é que nos manuais alemães destinados ao ensino do método na escolarização superior é raro o emprego do

4 Provavelmente inspirado por Heinrich Karl von Ludolf Sybel (1817-1885), a quem cita diretamente. BOURNE, Edward Gaylor. Ranke and the Beginning of the Seminary Method in Teaching History. In: BOURNE, Edward Gaylor. Essays in Historical Criticism. New York: Charles Scribner's Sons, 1901. p.265-274.

5 Bourne colhe essa informação de uma da história da historiografia produzida por Franz von Wegele WEGELE, Franz von. Geschichte der Deutschen Historiographie. Müchen: Oldembug, 1885. p.68-69. As demais, retira dos depoimentos sobre os exercícios praticados por contemporâneos de Ranke, a exemplo do texto de Georg Waitz. WAITZ, Georg. Die historischen Übungen zu Göttingen - Glückwunschschreiben an Leopold von Ranke, 20 februar 1867. Göttingen: Kaestner, 1867. 
étimo e demais elementos do seu campo semântico, a exemplo dos impressos de "Seminarien", "Seminarübungen", "Seminar" (Meister, 1913, p.4, p.8, p.23), "historischen Seminaren" (Meyer, 1902, p.55) e "Uebungen" (Droysen, 1882, p.82). ${ }^{6}$

Método e instituição de ensino: esses sentidos são ponto pacífico entre historiadores consultados. Sobre a emergência e as bases nas quais seria fundado o seminário histórico - Göttingen ou Berlim, por exemplo - e o papel atribuído aos codificadores dos princípios metódicos praticados no seu interior, são raros e divergentes os estudos especializados.

Entre os autores que recentemente se ocuparam da identidade profissional historiadora, J. Telman ${ }^{7}$ constrói seu argumento contestando a tese de W. Blanke, D. Fleischer e J. Rüsen (1984) de que tal fenômeno estaria relacionado às práticas de pesquisa em curso no final do século XVIII, em Göttingen, por exemplo. Para Telman, a universidade, nessa época, estava ocupada com o ensino e não, necessariamente, com a pesquisa histórica [historische Forschung] (Telman, 1993, p.143).

O seminário estabelecido logo após a fundação da universidade de Göttingen não era "de" história: era "de" filologia. Sobre o papel de Ranke na difusão dos seminários, Telman também pondera: "he was merely emulating the style in which he had been taught in the philological seminar at the University of Leipzig".

Dois anos depois, Bonnie G. Smith ${ }^{9}$ explorou a progressiva influência do seminário de Ranke, a partir de relatos dos ex-alunos. Ela insistiu sobre a relevância dos exercícios rankeanos e do estímulo gerado pelo

6 MEISTER, Aloys. Grundzüge der Historischen Methode. Leipzig: B.G. Teubner, 1913; MEYER, Eduard. Theorie und Methodik der Ceschichte. Halle: 1903: Max Niemeyer; DROYSEN, Johann Gustav. Grundriss der Historik. Leipzig: Von Veit, 1882.

7 O texto é a dissertação de doutorado, defendida na área de "modern European intellectual history, German history, and German literature", na Cornell University, em agosto de 1992.

8 "Ele estava simplesmente reproduzindo o estilo no qual foi ensinado no seminário filológico da Universidade de Leipzig" (TELMAN, 1993, p.140), tradução nossa.

9 Bonnie G. Smith é professora de história na Rutgers Univertity, New Jersey - EUA. Publicou The gender of history: men, women and historical practice, 1998. 
ambiente de sociabilidade para a institucionalização dos seminários históricos e dos "exercitationes historicae", em outros lugares da Alemanha (Smith, 1995, p.1160).

Por outro lado, escrevendo duas décadas à frente de Telman e de Smith e partindo, como Smith, de uma visão dominantemente internalista, Kasper Risbjerg Eskildsen ${ }^{10}$ foi taxativo: "séminaires [historiques], équipés de salles, de bibliothèques de références, de cartes et d'atlas, de l'éclairage au gaz, de bureaux et d'armoires"11 é fenômeno dos últimos quinze anos do século XIX, na Alemanha. Os seminários históricos descendem dos seminários de filologia e de pedagogia do século XVIII e foram usados como mecanismo para a formação de professores (Eskildsen, 2007, p.462-463). No caso de Ranke, afirma que mestre era um mau orador, ${ }^{12}$ atraindo, assim, poucos alunos aos raros seminários abertos pelo próprio, sendo incompreensível o lugar de fundador atribuído ao mestre de Berlim.

A "proveniência" pedagógica dos seminários históricos citados por Eskildsen foram preocupação de Otto Kruse, ${ }^{13}$ que diz pouco sobre os seminários "de história": entre 1812 e 1839, entre 22 seminários, apenas o de Könisberg (1832) é dedicado à disciplina. O seminário da Universidade de Göttingen é apontado como o primeiro: era uma "instituição" para a formação de professores que deveriam estudar todas as disciplinas ensináveis na escolarização básica: "philosophy, mathematics, physics, history and geography, old and modern languages, pedagogy and psychology" [filosofia, matemática, física, história e geografia, línguas antigas e modernas, pedagogia e psicologia]. Tempos depois, seminário foi empregado no ensino das línguas antigas - batizado como

10 Professor de história da ciência na Roskilde University, na Dinamarca. Estuda história German scholarship e história das ciências humanas (ESKILDSEN, 2013, p.26).

11 "Seminários históricos, equipamentos de salas, bibliotecas de referência, cartas e atlas, iluminação à gás, escritórios e armários" (ESKILDSEN, 2007, p.462), tradução nossa.

12 Frases sem coordenação, voz baixa e pronúncia veloz.

13 Professor da Zurich University of Applied Sciences, em Winterthur, Switzerland. 
“Seminarium Philologicum” (Kruse, 2006, p.337). -, marcando certa disciplinarização e consequente especialização. ${ }^{14}$

William Clark, ${ }^{15}$ último especialista em seminários alemães comentado neste texto, explorou o tema desde o início dos anos 1990. Suas teses acerca da emergência dessa instituição que "fused a particular style of teaching with a particular method of funding" 16 eram conhecidas por Telman, Smith, Eskildsen e Kruse. Para Clarke, os seminários que ganharam centralidade nas universidades alemãs, entre 1738 e 1832, provinham de dois tipos de instituição em vigor no século XVI: os colégios privados católicos e os seminários pedagógicos protestantes. $\mathrm{O}$ de Göttingen (1738) era modelar. Mesclava características das sociedades privadas e estatais. Seu diretor era indicado pelo mesmo financiador, o Estado. A organização, ainda que publicada pelo Estado, fundava-se nos clássicos estatutos das sociedades privadas. No interior de faculdades de artes e de filosofia, o seminário estava imerso em aura de "racionalidade" e "carisma" (Clark, 2006, posição 1999), mas somente após a administração de Christian Gottlob Heyne (1729-1812) - com a especialização nos trabalhos de filologia e pedagogia (1763) — o seminário de Göttingen inspiraria vários outros em quase todas as universidades alemãs, já na primeira metade do século XIX (Clark, 2006, posição 2158).

Com afirmamos no início deste tópico, foi proposital a escolha de cinco autores que partiram de interesses e aportes diferentes - além dos textos centenários de Bourne e Erben -, não necessariamente interagentes na escrita. Esse confronto nos possibilitou extrair significativos acordos e pôr à prova alguns argumentos cunhados pelos próprios. Assim, provisoriamente, podemos seguir no exame dos relatos

14 Para KRUSE, 2006, tais mudanças foram condicionadas pela emergência do neo-humanismo e também por uma conjuntural mudança de orientação das práticas formativas: da disputa medieval à escrita moderna.

15 William Clark é "visiting assistant professor" de história na Universidade da Califórnia, Los Angeles, e coeditor de The Sciences in Enlightened Europe. Disponível em: http://press.uchicago. edu/ucp/books/author/C/W/au5338174.html; Acesso em: 22 nov. 2015.

16 "Fundiu um estilo particular de ensino com um método particular de financiamento" (Clark, 2006, posição 1967), tradução nossa. 
dos missionários considerando que os primeiros seminários instituídos nas universidades alemãs se destinaram à formação de professores para os ensinos primário e/ou secundário. Foram práticas dos séculos XVI, transformadas, principalmente, em Göttingen, na segunda metade do século XVIII, incorporadas pelos historiadores, sobretudo, na segunda metade do século XIX. Neste tempo, contudo, seminários de universidades coexistiram com seminários de sociedades científicas e seminários praticados na casa do professor, sendo parte deles financiada pelo Estado. Assim, consideramos que, nos bem-sucedidos seminários - os modelares -, professores e bolsistas praticavam estudos filológicos e combinaram ensino e pesquisa no prioritário exercício da crítica de fontes.

Sabemos, entretanto, que os missionários da França, Bélgica, Argentina e Estados Unidos estiveram na Alemanha, justamente, nesse período de consolidação do - às vezes designado - modelo-seminário, já disciplinarizado, com o adjetivo "histórico", ou seja, nas duas últimas décadas do século XIX e na primeira do século XX. O que observaram, então, esses historiadores? O que mais lhes chamou a atenção? Como traduziram a sua experiência de compiladores das práticas e das virtudes do historiador profissional? Em que medida os seus interesses os colocam distantes (ou próximos) das ressignificações operadas pelos cinco especialistas do nosso tempo?

\section{AS INSUFICIÊNCIAS DOS SEMINÁRIOS Históricos ALEMÃes SEgundo Charles Seignobos}

Em língua francesa, belgas e franceses rivalizam-se no interesse pela experiência dos alemães. Na França, ao menos 13 estudos foram publicados nas duas últimas décadas do século XIX, na Revue Internationale d'Enseignement. Essa instituição fora criada com estímulos do Estado francês para investigar e refletir sobre novos modelos de ensino superior implantáveis no país, alternativos ao destroçado modelo napoleônico e ao medievalismo presente nas congêneres instituições inglesas. Segundo Cristophe Charle, os franceses estavam interessados na experiência 
alemã, mas "a República queria a ciência e também a democracia". ${ }^{17}$ Desses estudos, três eram sobre ensino superior de história. ${ }^{18} \mathrm{Um}$ deles nos interessa particularmente porque foi escrito pelo coautor do manual mais traduzido e citado no Ocidente - Introduction aux études historiques (1898): Charles Seignobos. ${ }^{19}$

Como afirmou Cristophe Charles, franceses foram à Alemanha, mas mostraram-se bastante críticos ao seu modelo universitário. Contudo, motivos outros - endógenos ao mundo de determinado grupo de historiadores, adiante rotulados como "metódicos" - dariam sentido a essa repulsa, para além do caráter aristocrático e monocrático da experiência política e da diversa política-educacional alemã: questões de método. Aluno da École Normale Supéurieure, aos 20 anos (1874), Seignobos cumpriu o rito da "agrégation"20 (1877) e foi presenteado com uma bolsa de estudos de dois anos na Alemanha. Estava em Munique, em abril de 1879, quando agradeceu por carta a indicação do seu nome para o posto de "maître de conférences" na Universidade de Dijon, assumido a 18 de julho de 1879 (Prost, 1994, p.102). ${ }^{21}$ Do seu estágio, vieram a público os

17 Vem daí o título-tese do texto do historiador Chistophe Charle ao examinar o interesse da França na experiência do outro lado do [Reno]: "Le impossible modele allemand", CHARLE, 1994.

18 O especialista em educação Edmond Dreyfus-Brisac apresenta-se como o primeiro francês a oferecer um relato sobre o ensino superior na Alemanha. DREYFUS-BRISAC, Edmond. L'Université de Bonn et l'Enseignement Supérieur en Allemagne. Bulletin (Société pour l'Étude des Questions d'Enseignement Supérieur). Paris: Hachette, p.01-158, 1878.

19 Vários outros profissionais interessaram-se pelas apropriações francesas sobre o ensino superior da Alemanha, a exemplo dos sociólogos A. Sorel, H.. Taine, E. Bougeois, J. Dietz, M. Leclerc, A. Lebon. VANNEUVILLE, 2002, p.71. Nessa passagem, ele compara as práticas alemãs às francesas: "Le séminaire historique a pour objet d'initier ses membres aux méthodes de la recherche et aux procédés de l'exposition historique. Les quatre sections qui le composent doivent être divisées de telle sorte que l'ensemble de l'histoire, y compris les sciences auxiliaires, y soit l'objet d'études approfondies [...]. Les exercices de l'école des Hautes-Études de Paris donnent une idée assez exacte des travaux des séminaires allemands, avec cette différence que cet établissement n'est pas intimement uni à l'enseignement des Facultés de l'État." (DREYFUS-BRISAC, 1878, p.134, p.150, p.158).

20 Processo de "agregação" (tradução nossa), a nominação de um professor a um cargo "titular" em uma universidade.

21 Outras apreciações positivas da obra de Seignobos estão em KEYLOR, 1975, p.75-86 e BOER, 1998, p.429. As mais ácidas críticas, aos textos de método e manuais de síntese escolar ainda 
textos: "Étude sur l'Université de Goetingue" (1878) e "Lenseignement de l'histoire dans les universités allemandes" (1880). ${ }^{22}$

O segundo texto, o mais abrangente e também o mais crítico, reproduz as principais características anunciadas no primeiro: variação de "método" - momentos didáticos estabelecidos para os alunos -, ênfase nos trabalhos de crítica documental e segregação da "art de la représentation (Darstellung) [...] aux grands historiens" 23 - o que, na França, segundo Seignobos, seria chamado "l'histoire” (Seignobos, 1878, p.189-190).

Para Seignobos, seminário é a tradução de "Seminarium”. Designa uma modalidade de ensino, onde são praticados os exercícios e os trabalhos escritos. Parte dessa descrição o francês extrai do famoso discurso de Sybel: "Die deutschen und die auswärtigen Universitäten" ["As universidades alemãs e estrangeiras" (1868)]. Seminários são uma forma de ensino ao lado dos cursos públicos que, por sua vez, subdividem-se quanto aos custos - pagos e gratuitos - e finalidades - patrióticas (história moderna) e instrutivas (histórias antiga e média). Cursos são exposições orais. Já os exercícios são exposições orais sobre as artes de fazer-aplicar tais orientações por parte dos alunos.

Seminário é também um local abstrato, referido com propriedade ou criação de um "savant" [erudito] ou do Estado. Deste último tipo são os chamados "séminaires historiques d'État" [seminários históricos de Estado] do professor de Carl Friedrich Johannes von Noorden (1833/1883): um lugar de publicação de documentos e crítica de textos, de produção de manuais de história universal, por exemplo, de preparação dos candidatos ao exame de Estado para a função de professor do ginásio, de formação do historiador, ou seja, onde se aprende a pesquisar história, produzir textos escritos que se podem transformar em teses de

são aquelas desferidas por FEBVRE, 1952 e MARROR, 1954.

22 SEIGNOBOS, Charles. L'enseignment de l'histoire dans les universités allemandes. Revue Internationale de l'Enseignement, Paris, vol. 1, p.564-600, 1880; L'Université de Goettingue. Bulletin (Société pour l'Étude des Questions d'Enseignement Supérieur). Paris: Hachette, p.158, 1878.

23 “Arte da representação (idem ou exposição) [...] os grandes historiadores". Tradução nossa. 
doutorado. Seminário é, por fim, uma edificação constituída por biblioteca e salas de trabalho.

Não obstante ser uma espécie de escola do historiador, o seminário alemão é incompleto. Seus responsáveis negligenciam a operação mais importante - a composição - exercitando-se, tão somente, na crítica filológica. ${ }^{24}$ Sem a composição, os alunos ficam desprovidos do sentido histórico e, por isso, não são transformados em completos sábios. Esse valor atribuído às práticas do seminário se estende, obviamente, à percepção que a maioria dos professores experimenta sobre o saber: "L'histoire [...] se renferme aujourd'hui dans la connaissance et la critique des documents et le récit des évènements politiques". ${ }^{25}$

A incompletude também é demonstrada em termos de oratória. Até se tentou, informa Seignobos, inserir uma terceira operação no seminário, mas não foi à frente. Nem mesmo nas "associations scientifiques d'étudiants". Contudo, "ni les étudiants néprouvent vraiment le besoin d'apprendre à parler, ni les professeurs ne connaissent assez l'art de faire une leçon pour l'enseigner". ${ }^{26}$

Pela crítica, já podemos pressupor a ideia de método histórico [“ $m e ́$ thode historique"]: atividades relativas ao "contrôle des témoignages ${ }^{27}$ [sincero ou de má fé? Bem informado ou ignorante?] et la critique des textes [original ou cópia?]" (Seignobos, 1880, p.586, p.578), mas que não segue "tradition fixe". Cada professor procede segundo sua vontade. O método histórico ideal, segundo Seignobos, estaria, porém, na inserção de um terceiro grupo de atividades destinados a exercitar "à la parole"

24 Tal vício não é de todo reprovável. No citado Seminaire de Noorden, em Bonn (1876-1877), por exemplo, os alunos aprendem a valorizar as fontes primárias e a desconfiar dos erros e mentiras comunicados pelas fontes, enfim, conscientizam-se de que "l'histoire [...] est affaire de critique, non d'autorité". [História é questão de crítica, não de autoridade] (SEIGNOBOS, 1880, p.585-586), tradução nossa.

25 "A história está contida hoje no conhecimento e na crítica dos documentos e na narrativa dos eventos políticos." (SEIGNOBOS, 1880, p.371-372), tradução nossa.

26 "Nem os estudantes sentem uma necessidade real de aprender a falar, nem os professores conhecem suficientemente a arte de fazer uma lição que os ensine." (SEIGNOBOS, 1880, p.585), tradução nossa.

27 "Controle de testemunhas". 
(Seignobos, 1880, p.585). O método deveria estar configurado em três operações: " $1^{\circ}$ publication des documents; $2^{\circ}$ critique des textes; $3^{\circ}$. Composition historique. De ces trois opérations, les Allemands n'en admettent que deux dans l'enseignement".28

Ainda que solitário, um segundo sentido de método chama a atenção, justamente por conservar um princípio empregado séculos antes: a ideia de considerar historicidade das coisas, ou seja, abordar os objetos a partir do seu vir a ser. Esse método histórico é traduzido como um "principe... la loi du développement progressif" [princípio... a lei do desenvolvimento progressivo]. Ele explica. É uma espécie de "croyance, une institution, une forme littéraire, ne s'expliquent que par la série de celles qui l'ont précéde; et toutes études sur ces matières doit être conduite suivant l'ordre des temps, c'est-à-dire historiquement". ${ }^{29}$

Apesar das variações semânticas, o sentido que veio a dominar a sua obra foi mesmo a tríade heurística, crítica e composição, claramente distintas em Introduction aux études historiques (1898) e no La méthode historique appliquée aux sciences sociales (1901). Nas duas obras, Seibnobos manteve as críticas aos seminários e exercícios alemães. Ambas resultaram de cursos ministrados, respectivamente, na Sorbonne (1897-1898) e no Collège Livre des Sciences Sociales (1899-1901). No que diz respeito aos seminários, como modalidade de ensino ou lugar de crítica documental, eles já existiam na França - para nos limitarmos ao período da transnacionalização - desde 1868, com as iniciativas de Gabriel Monod (1844-1812) - ex-aluno de Berlin e de Göttingen — na École Normal Supérieure e na École Pratique des Hautes Études. ${ }^{30}$

28 " $1{ }^{\circ}$ publicação dos documentos; $2^{\circ}$ crítica dos textos; $3^{\circ}$ composição histórica. Das três operações, os alemães não admitem mais que duas no ensino" (SEIGNOBOS, 1880, p.586-587), tradução nossa.

29 "Crença, uma instituição ou uma forma literária se explicam pela série daquilo que as precedeu; e todo estudo sobre estas matérias devem ser conduzidos sob a ordem dos tempos, ou seja, historicamente." (SEIGNOBOS, 1880, p.571), tradução nossa.

30 MONOD, Gabriel. Études critiques sur les sources de l'histoire merovingienne. (Collection Historique, vol. 2 - Recueil de travaux originaux traduits relatifs aux sciences historiques). Paris: A. Franck, 1872, p.01. 


\section{O ENTUSIASMO BELGA COM OS “CURSOS PRÁTICOS” GERMÂNICOS}

Os cursos de caráter prático, que impressionaram e, em parte, decepcionariam Seignobos também são o alvo de historiadores ${ }^{31}$ da Bélgica, com destaque para Paul Fredericq ${ }^{32}$ (1850-1920). Fredericq cumpriu missão do Ministro da Instrução Pública para estudar o ensino de história em universidades estrangeiras. ${ }^{33}$ Suas "excursions scientifiques" [excursões científicas] à Alemanha ocorreram entre 1881 e 1882 (Fredericq, 1882, p.18). As intituladas "Notes et impressions de voyage" [notas e impressões de viagem], colhidas junto às universidades de Berlin, Götingen e Leipzig foram publicadas ainda em 1882, tipificando o ensino de história em cursos teóricos e cursos práticos.

Os teóricos são conjuntos de aulas expositivas, mas que não deixam ao largo os conteúdos metahistóricos, mediante manuais de introdução aos estudos históricos. Do curso teórico de História moderna, ofertado por Gustav Droysen (1838-1908) — o filho de J. G. Droysen —, ele afirma: "presque tous les élèves étaient munis du Manuel du professeur, Grundriss der Historik (2e. édition, Leipzig, 1875)"."34

31 O belga Godefroide Kurth (1847-1916) também visitou a Alemanha e com igual intenção descreveu os seminários alemães como cursos teóricos privados ou estatais, cultivados em sociedades históricas, constituídas por estudantes ou por iniciativa do professor, no interior da universidade: "Séminaire historique" de Wuttke, que estudava fontes da história antiga dos povos eslavos, e o "Seminaire historique" de Sylbel em Bonn. KURTH, Godefreide. De l'enseignement de l'histoire en Allemagne. Revue de l'instruction Publique (Supérieure et Moyenne) en Belgique, Gand, t. 19, p.88-100, 1876, p.18, p.88, p.92.

32 Paul Fredericq (1850-1920) doutorou-se em História e tornou-se professor da Universidade de Liège e também da Universidade de Gand. Especializou-se em história política dos Países Baixos, história da Inquisição e também do ensino superior de história na Europa. Dividiu cursos e estudos com Henri Pirrene, de quem recebeu grande influência em Liège. BENTLEY, 2007, p.419.

33 Ele estudou o tema na Holanda, Inglaterra, França e Alemanha. FREDERICQ, Paul. De l'enseignement supérieur de l'histoire: notes et impressions de Voyage. Revue de l'Instruction publique (Supérieure et Moyenne) en Belgique. [Bruxelles], t. 25, n. 4, p.18-52, 1882; Lorigine et les développements des cours pratiques d'histoire dans lenseignement supérieur en Belgique. Liège: Henri Toxcelet, [1901].

34 "Quase todos os estudantes portavam o manual do professor, Grundriss der Historik", tradução nossa. 
Os cours pratiques 35 são nomeados como "exercícios práticos", "cursos práticos íntimos", "lições práticas". Narrando do ponto de vista do professor, Fredericq lista as operações básicas de oito mestres, cujas práticas diferem bastante. No curso de Bresslau, por exemplo, ministrado em sua residência, os alunos são submetidos a uma lista de questões, à escolha de uma dessas questões, à escrita de dissertações, à crítica das dissertações por parte de uma dupla de alunos e ao debate coletivo. $\mathrm{Na}$ Universidade de Halle, Droysen segue outras etapas: apresenta uma questão; apresenta fontes impressas sobre as quais os alunos se debruçarão para responder à questão inicial; apresenta correspondências e brochuras; solicita a comparação das fontes impressas com as cartas e brochuras; solicita que os alunos estipulem valor das fontes e, ainda, que escrevam e apresentem dissertações e trabalhos aos colegas.

Cursos e exercícios práticos são expressões constantes e nos remetem ao termo método. Mas a baixa frequência do vocábulo é o que constatamos. Não obstante registrar um curso de metodologia histórica na Universidade de Berlim (Frederick, 1882, p.18) e outro de metodologia da ciência geográfica na Universidade de Halle (Fredericq, 1882, p.37), método é empregado dominantemente para designar ou qualificar um conjunto de operações do ensino: “...avec um maître aussi competent [professor Schum], une méthode aussi sûre et un appareil scientifique aussi complet, l'enseignement pratique de la paléographie et de la diplomatique devient particulièrement fécond"; 36 "Tous les élèves écrivent sous la dictée cette espèce d’ordre du jour détaille et méthodique”; 37 “... le professeur [Arndt] le discute [a dissertação] avec l'auteur dans son cabinet; mais le cours pratique reste exclusivement oral et le professeur y emploie surtout la méthode socratique" ${ }^{38}$ A única referência que

35 Conferir inventário dos termos e sentidos no Apêndice deste texto.

36 "com um mestre competente, um método também certo e um aparato científico completo, o ensino prático da paleografia e da diplomática tornam-se especialmente frutíferas" (FREDERICQ, 1882, p.38-39), tradução nossa.

37 "Todos os estudantes escrevem por ditado essa espécie de ordem do dia detalhada e metodicamente" (FREDERICQ, 1882, p.42), tradução nossa.

38 “- o professor discute [a dissertação] com o autor dentro de seu escritório; mas o curso prático 
foge a esse sentido também não remete o leitor às práticas dos cursos e seminários: "M. Koser appréciait aussi la valeur des principaux auteurs qui ont écrit sur l'histoire moderne. Je lui ai entendu exposer très nettement la portée de la révolution opérée par Voltaire qui avait usé en partie sa méthode nouvelle dans les lettres sur l'histoire de son ami Lord Bolingbroke" ${ }^{39}$

Mencionados em menor proporção, ${ }^{40}$ os seminários também conservam à ideia de ensino. Trata-se de "gênero de ensino", praticado sob a orientação e a subvenção do Estado. Alguns são bem aquinhoados em termos de biblioteca e espaço para leituras e exposições. As práticas e o conteúdo substantivo, entretanto, são tão variados quanto os equivalentes nos gabinetes instalados na casa do professor (Fredericq, 1882, p.27).

Curso prático, ao menos em uma ocasião, é também compreendido como "petite société historique" [pequena sociedade histórica] (Fredericq, 1882 , p.48) - a exemplo daquelas abonadas por Droysen e Bresslau. Contudo, as dezessete "sociétés historiques d'étudiants" [sociedades históricas de estudantes] que inventariou são vistas como instituição de educação auxiliar à formação superior em história, junto aos cursos teóricos e cursos práticos. Naqueles espaços, os alunos atualizam e compartilham informações sobre artigos e dissertações recentemente publicadas, além de exercitar a retórica, tanto em termos de produção acadêmica como na seara da literatura ficcional.

No geral, Fredericq foi um entusiasmado leitor e visitante da experiência alemã dos cursos práticos e dos seminários, seja entre os professores mais jovens, seja na presença do veterano Ranke. Ele mostrouse bastante agradecido pela receptividade dos alemães e, ainda, pelo estoque de referências sobre os procedimentos de ensino destinadas à

se mantém exclusivamente oral e o professor emprega acima de tudo o método socrático" (FREDERICQ, 1882, p.43-44), tradução nossa.

39 "M. Koser aprecia também o valor dos principais autores que escreveram sobre a história moderna. Eu o ouvi explicar claramente o escopo da revolução operada por Voltaire, que foi usada em parte como um novo método dentro das cartas sobre a história de seu amigo Lord Bolingbroke." (FREDERICQ, 1882, p.26), tradução nossa.

40 Conferir inventário dos termos e sentidos no Apêndice deste texto. 
formação do "aluno" 41 de história na Bélgica, sobre a própria história da França e da Bélgica, o presente e as origens dos cursos práticos do ensino superior de história.

Ao retornar, incluiu em seus "cours pratiques" (1882-1883) algumas técnicas observadas no seminário do prof. Conrad, de Economia Política, na Universidade de Halle (Fredericq, [1901], p.49). ${ }^{42}$ Tratava-se da preleção, seguida de debates, coordenada pelo professor; anotações dos alunos sobre conclusões dos debates; leitura do resumo dos alunos e retificação dos escritos e posterior inclusão dos resumos nos anais do "cours" - que poderia durar até três anos - e publicação de uma dissertação coletiva.

Mas os "cours pratiques" - "exercices historique", "exercices de critique", "dissertations" etc. - somente receberam reforço alemão, e nas quatro universidades belgas, após as iniciativas de Godefroide Kurth (1847-1916), ${ }^{43}$ que também visitara os seminários de Wuttk e Sylbell e Droysen, sete anos antes da missão de Fredericq. "Cours pratiques", além disso, já existiam legalmente e efetivamente, desde meados do século XIX, como instrumento de formação de professores na Escola Normal (Fredericq, [1901], p.5, p.8). Mas, até 1890, nunca possuíram as salas de estudos para os alunos, tampouco as bibliotecas especializadas ao modelo dos seminários alemães (Kurth, [1901], p.196). Esse tipo de estrutura, somente os EUA conseguiram efetivar, ainda no final do século XIX.

\section{DA EXCELÊNCIA GERMÂNICA AO SEMINÁRIO EMINENTEMENTE “AMERICANO”}

Herbert B. Adams (1850-1901) foi apenas um entre os vários pós-graduandos que cumpriram estágio em universidades alemãs e que traduziram suas

41 Grafado desse modo, sem os termos "professor" ou "historiador".

42 Colchetes em referências indicam data provável de publicação.

43 KURTH, 1876, t. 19, p.88-100; KURTH, Godefroide. Discours. In: FREDERICQ, Paul. L’origine et les développements des cours pratiques d'histoire dans l'enseignement supérieur en Belgique. Liège: Henri Toxcelent, [1901]. p.191-198. 
experiências com os seminários. Estudou por duas vezes em Heidelberg. Na primeira (1874), interessou-se por história da cultura [Kulturgeschichte], focada na antiguidade clássica e oriental e literatura, praticadas por Ernest Curtius (1814-1896), Karl Richard Lepsius (1810-1884) e Hermann Grim (1928-1901), estudando com afinco a filosofia de Droysen, exposta nos Grundriss der Historik. Na segunda (1875-1876), frequentou os seminários de Eduard Winkelmann (1838-1896) e o seminário de Bernhard Erdmannsdöffer (1834-1901), com quem praticou, respectivamente, os "historical exercises" ["Quellenstudien”] de tradução, crítica de crônicas e comparação com outras fontes coevas e também a "research topics" ["Kleine Arbeiten"] (Cunningham, 1981, p.266-269). O que viria a defender como métodos históricos, portanto, teria provindo tanto de cursos quanto de seminários.

Voltando aos EUA, recomendado pelo professor alemão Johann Caspar Bluntschli (1808-1881), tornou-se professor Universidade Johns Hopkins (Baltimore-EUA). Seu depoimento, publicado como "New Methods of Study in History" (1884) ${ }^{44}$ divulga as atividades desenvolvidas no "Seminary method" na Johns Hopkins University, no Baltimore Seminary e também a sua experiência de aluno em Berlim, entre 1874 e 1875 (Adams, 1884, p.75). Nesse texto (Adams, 1884, p.25-136), seminário é um dos quatro clássicos métodos de ensino: "the topical method, the comparative method, the co-operative method, and the seminary or laboratory method". ${ }^{4}$

44 A exemplo das experiências belgas e francesas, vários são os depoimentos de egressos estadunidenses sobre os seminários germânicos. Charles Gross [1857-1909], doutor em filosofia pela Universidade de Gottingen e especialista em história municipal e legislação medieval inglesa também deixou depoimento sobre os seminários, copidescados por ADAMS, Herbert B. New methods of study in history. In: Historical and political science, vol. 2: Institutions and economics. Baltimore: Johns Hopkins University, 1884, p.70-72. Dignos de nota foram também os trabalhos de Fred Morrow Fling (1860-1931), da Universidade de Nebrascka, que produziu manual de introdução à história, inspirado, inclusive, nas aulas de Bernheim (FLING, 1899) e de Frank Hugh Foster (1851-1935), egresso de Leipzig e autor de manual sobre o emprego da técnica do seminário nos colleges. FLING, Fred Morrow. Outline of Historical Method. Lincoln: J. H. Miller, 1899; FOSTER, Frank Hugh. The Seminary Method of Original Study in the Historical Sciences. New York: Charles Scribner’s Sons, 1888.

45 "O método tópico, o método comparativo, o método cooperativo e o seminário ou método de laboratório" (ADAMS, 1884, p.25), tradução nossa. 
Definido como método de ensino aplicado à formação superior, o seminário tem "origem" marcada no trabalho de Ranke, desde 1825, segundo o autor. Foi o alemão quem primeiro transformou the "Seminarium into a laboratory of [historical] science". ${ }^{46}$ Nessa menção, Adams emprega como sinônimos quatro termos significativos: "Seminarium", "laboratory of science" [laboratório de ciência], "exercises in historical investigation" [exercícios em investigação histórica] e "methods" [métodos].

$\mathrm{Na}$ descrição da sua experiência ${ }^{47}$ contudo, não há homogeneidade para o sentido de seminário, seja em sua forma isolada, seja em sua forma composta: ${ }^{48}$ "seminary" [seminário], "seminary method" [método de seminário], "historical seminary" [ seminário histórico], "seminary -work" [trabalho de seminário]. Seminário, portanto, é expresso como método de ensino superior de uso generalizado na Alemanha - seminário - , por várias cadeiras e ramos do conhecimento - método de seminário no seminário filológico, seminário arqueológico etc. —, inclusive aquelas que estão desacompanhadas de expressões como "história de" ou "histórico." Mas seminário é também o lugar onde os métodos investigativos são transmitidos e praticados pelos noviços - seminário de trabalho, principalmente em sua própria residência -; e laboratório

46 "A transformação do seminário em um laboratório de ciência foi atingida primeiramente a mais de cinquenta anos atrás pelo grande historiador alemão Leopold von Ranke. Ele nasceu no ano de 1795 e foi Professor de História na Universidade de Berlim desde 1825. Ali, por volta de 1830, ele institucionalizou aqueles exercícios práticos em investigação histórica (exercitationes historicae), que desenvolveram a próxima escola de historiadores. Homens como Waitz, Giesebrecht, Wattenbach, Von Sybel, Adolph Schmidt e Duncker devem seus métodos a esse pai da ciência histórica." (ADAMS, 1884, p.65), tradução nossa.

47 Para redigir o tópico, Barns fundamenta-se na própria experiência nas universidades de Heidelberg (professores Grimm, Stark, [Koechly, Bluntschli e Knies]), na descrição de Dreyfus -Brisac sobre a Universidade de Bonn (professores Held e Bona-Meyer), do estadunidense Charles Gross (professores Bresslau, Gieselbrecht, Noorden, Droysen, Weizsäcker e Pauli), dos já comentados Paul Fredericq e Charles Seignobos, como também do relato de Edward Engel sobre o seminário de estatística em Berlim e da visita de Kurth à Alemanha entre 1875 e 1875. Aqui, analisamos apenas a experiência direta de BARNES, Herbert Baxter. Seminary libraries and University extension. Baltimore: N. Murray; Johns Hopkins University, 1887.

$48 \mathrm{O}$ sentido considerado neste texto é o dominante estatisticamente, ou seja, o que atinge dois terços das referências. 
de trabalho do historiador, ou seja, lugar onde são praticados os exercícios de investigação histórica. Ainda assim, é possível apresentar " $a$ few seminary types” [alguns tipos de seminário] (Adams, 1884, p.65).

No seminário de grego, promovido por Hermann August Theodor Köchly (1815-1876), a exposição de um autor é a primeira tarefa do aluno. Em seguida, o mesmo procede à tradução e às críticas ao autor lido. Ao professor cabe o julgamento das críticas e a indicação dos defeitos do trabalho do aluno. Já no seminário de direito constitucional e internacional de J. C. Bluntschli, também na Universidade de Heildelberg - típico seminário de trabalho - , o professor expõe textos constitucionais, por exemplo, e os compara. Apresenta questões aos alunos e solicita que investiguem e produzam relatos, comunicando os resultados da investigação (Adams, 1884, p.65-68).

O sentido de método é mais restrito que o de seminário: conjunto de procedimentos para o ensino que constitui o seminário pedagógico e o seminário histórico. É também o conjunto de procedimentos específicos da ciência da história, que podem ser aplicados, por exemplo, no seminário de economia política. Pela descrição, um suposto método histórico seria caracterizado "in the reading and discussion of original papers by his pupils upon assigned topics". ${ }^{4}$

A variedade semântica de método e de seminário nos impede, por ora, de chegar a uma conclusão segura sobre o valor atribuído por Adams: método de ensino, conjunto de métodos de ensino, exercícios de investigação, espaço de investigação e escrita da história etc. Mas é clara a superioridade do seminário como exercícios práticos sobre o seminário como exposição oral e formação das habilidades do instrutor. E é perfeitamente demonstrável como a expressão "laboratory method" foi difundida por várias universidades dos EUA, inclusive na forma de bibliotecas especializadas, na última década do século XIX. Ele mesmo esforçou-se e conseguiu adquirir a biblioteca do seu ex-professor Bluntschli. Planejou e fez construir edifícios especializados para

49 "Na leitura e discussão dos artigos originais pelos alunos sob um tópico designado" (ADAMNS, 1884, p.69). 
a função. Trouxe, então, ideias e materiais germânicos - um pedaço de Heidelberg - para o estado de Maryland e de lá exportou o "colonial system of the Johns Hopkins University", formando historiadores como J. F. Jameson, Henry C. Adams, Woodrow Wilson e F. J. Turner (Eschenbacher, 1964, p.82). Adams, por fim, quis transformar o seminário em atividade de extensão universitária, requisitando a construção de bibliotecas, próximas a centros de educação superior, onde seriam promovidos cursos de leitura, escrita e investigação para não universitários, como estratégia, inclusive, de harmonizar as relações entre capital e trabalho (Adams, 1887, p.21-23).

\section{OS SEMINÁRIOS DE LAMPRECHT COMO MODELO para a Argentina de Quesada}

A ideia de seminário-edificação também está presente no relatório de Ernesto Quesada (1858-1934). Ele já era historiador e jurista de renome quando foi convidado a "informar-se de la organización y método de los cursos superiores de historia, en una ó más universidades de Alemania". ${ }^{50}$ Nas orientações governamentais emitidas em 1908, o missivista Rodolfo Rivarola, ${ }^{51}$ decano da Faculdade de Ciências Jurídicas e Sociais da Universidade de La Plata, deixou claro o objetivo da missão atribuída a Ernesto Quesada: "estabelecer el curso de historia en la sección de filosofia, historia y letras, que deberá fundarse como anexa à esta facultad"

50 Ricardo Rojas (1882-1957), professor das universidades La Plata e de Buenos Ayres, viajou à Europa, em 1907, em busca de experiências que relacionassem o ensino de história à construção da nacionalidade. Mas, como afirma o próprio Quesada, Rojas não dominava o idioma e produziu relato a partir de fontes secundárias colhidas na França, Bélgica, Espanha e Itália, principalmente. Contudo, deixou indícios do seu apego às práticas germânicas em $\mathrm{La}$ restauración nacionalista (1909): “'Alemania, Alemania sobre todos, sobre todo en el mundo!' Tal país nos interesa, a nosotros los argentinos, que estamos forjando una nación, pues ésta ha de ser, según el sueño de todos, fuerte y dominada, pero con fortaleza de espíritu”. ROJAS, Ricardo. La restauración nacionalista. La Plata: UNIPE: Editorial Universitaria, 2010 [1909]. p.143. Grifos do autor.

51 RIVAROLA, Rodolfo. Correspondência endereçada a Ernesto Quesada. La Plata, 15 nov. 1908. In: QUESADA, Enesto. La enseñanza de la historia en las universidades alemanas. La Plata: Facultad de Ciencias Jurídicas y Sociales (Universidad Nacional de La Plata), 1910. p.07-08. 
(Rivarola, 1908, p.07). O resultado da tarefa foi exposto em um livro de 1317 páginas no qual dissertava sobre a história do ensino de história na Alemanha, nos níveis primário, secundário e superior, ${ }^{52}$ entre os séculos XV e XX. Nessa obra, as primeiras referências a "seminario" e "método" estão relacionadas às políticas públicas educacionais prussianas para a formação de professores primários. Esses seminários tiveram os trabalhos filológicos de Wolf em Halle e de Gedike em Berlim como modelo. Os professores do ensino secundário eram preparados em universidades (Quesada, 1910, p.45, p.95).

Quanto ao "método", o termo é empregado para descrever conjunto de técnicas de retenção do conhecimento histórico (Quesada, 1910, p.48), vigentes entre a segunda metade do século XVIII e a primeira do XIX - "la mnemotécnica gramatical" e "la imitación de la frase" (Quesada, 1910, p.63). Método também é entendido como modos de distribuição do conteúdo substantivo nos programas e currículos. ${ }^{53}$ No ensino superior, "seminários universitários" são os termos que demonstram a renovação na história, após a reforma da Universidade de Berlim. As "origens" e o "testemunho" destoam dos missionários que vimos até aqui. Quesada afirma que o primeiro "seminário de la historia" foi estabelecido na Universidade de Könisberg, em 1832 e baseia-se no discurso de Fichte para exemplificar o sentido de seminário que vai dominar o restante do seu relato. ${ }^{54}$ Contudo, não deixa de citar o já referido Waitz e o seu "famoso seminário histórico" em Göttingen, de onde proveio (segundo o argentino) a maior parte dos historiadores

$52 \mathrm{O}$ ensino superior ocupa $3 / 4$ desse livro.

53 Etnográfico e sincrônico, cronológico ou progressivo, retrospectivo, épocas de cultura, regressivo, herbartiano-zilleriano, regressivo, de agrupamento, comparativo, do calendário, geográfico, eclesiástico, continuado, concêntrico objetivo, concêntrico subjetivo. QUESADA, 1910, p.159-179.

54 "Los profesores debían considerar-se, ante todo, como hombres de ciencia y basar su autoridad en la investigación metódica de su materia, enseñando à los estudiantes à practicarla; de ahí la gran característica del siglo XIX: la institución de los 'seminarios universitarios' para ahondar la investigación científica, y apropiar-se métodos y criterios, buscando sólo la verdad y el ejercicio de la crítica personalísima, sin estar hostigado por exámenes escolares y por planes de estudios obligatorios, como en siglo XIX" (QUESADA, 1910, p.73). 
alemães do século XIX (Quesada, 1910, p.105). Göttingen é também o lugar de explícitas diferenças entre um seminário "histórico y em outro essencialmente pedagógico":

En el primero, el curso de seminario se ocupa de la metodología y crítica histórica, enseñando à practicar una investigación cualquiera, à manejar las fuentes, à conocer la bibliografía, à formar el criterio del indagador y del futuro historiador [...] en el seminario pedagógico, cuando se trata de historia, no se enseña à investigar directamente sobre las fuentes, sino que se emplea el año disponible - el Seminarjahr: para distinguirlo del Probejarh, que requiere el ejercicio de la cátedra en escuelas públicas de aplicación - haciéndoles presentar monografías sobre temas históricos, que se discuten, pero siempre del punto de vista pedagógico de su enseñanza, las diferentes maneras y sistemas de enseñarla en las escuelas, y el modo de proceder del maestro respecto de los alumnos (Quesada, 1910, p.363-364). Grifos do autor.

$\mathrm{Na}$ descrição da organização do ensino nas 22 universidades alemãs, Quesada também diferencia "metodologia de la enseñanza universitária de la historia" e "método científico de ir à las fuentes históricas" (Quesada, 1910, p.542). O primeiro é livre. Cada professor "forma escuela" (Quesada, 1910, p.894). O segundo é de uso generalizado: "Se parte siempre de la fuente histórica, del documento de primera mano: se le interpreta à la luz de la filologia y de las disciplinas auxilares de la historia; se le compara con todos los trabajos análogos existentes; se practica, en una palavra, una investigación admirablemente meticulosa, entes de formular conclusión alguna" (Quesada, 1910, p.544).

Das dezenas de iniciativas listadas que replicam esses procedimentos, entre as quais as praticadas por Bernheim e Droysen, Quesada opta pela inovação protagonizada em Leipzig por Karl Gottard Lamprecht (1856-1915): a reunião de seminários em um Instituto - instalado em prédio especialmente projetado para o trabalho em grupo e a consulta a fontes de natureza diversa - e a ampliação da escala de pesquisa - o estudo da história universal de caráter sociológico (generalizante). 
Esta é a alternativa indicada por Quesada para a instalação de formação superior em história na Argentina. O modelo de Lamprecht, na Universidade Nacional de La Plata, faria reunir todas as cadeiras de história em um só lugar, situadas em salas específicas. Simultaneamente, formaria os alunos na leitura de fontes, segundo técnicas das diversas ciências auxiliares e proveria, futuramente, o conhecimento progressivo da Argentina, da América, da Europa e, por fim, dos demais países do globo sob ideal generalizante (sociológico). Seminário seria tanto um modo de ensinar quanto uma instituição edificada cujos cômodos estariam dispostos em uma espécie de linha de montagem: dos rudimentos metahistóricos para os conteúdos substantivos em progressão do próximo ao distante. Seria enfim, a transformação do "exclusivo laboratorio erudito de investigaciones de la edad media - carácter hoy general en la mayoría de los seminarios históricos alemanes - para convertirse en institutos históricos, que contengan diversos seminarios especiales, pero orientados con el mismo espíritu" (Quesada, 1910, p.1138).

Não há notícias de que o instituto planejado de Quesada tenha sido construído. Seu livro foi bem recebido, em ambiente onde apenas Antonio Dellepiane ensinava rudimentos do método sob aliança com as ciências sociais (1910) na Faculdade de Filosofia e Letras da Universidade de Buenos Aires (Bunge, 1911, p.07). Mas é provável que as escolhas germânicas de Quesada - professadas na docência em sociologia, na Faculdade de Letras e na Escola Normal Superior de Buenos Aires - sejam compreendidas a partir da dominante abordagem sociológica acerca do passado argentino, conquistada desde meados do século XIX. A não efetivação do seu projeto, entretanto, está ligada à guinada à francesa sofrida pela Faculdade de Filosofia no sentido de formar professores - ao contrário da ênfase em ciências puras - , principalmente no início da terceira década do século XX (Buchbinder, 2011, p.163-164). No plano historiográfico, o instituto - e a proposta lampreschtiana - talvez tenham sido sepultadas quando o professor da Faculdade de Direito, Juan Agustín Garcia (1862-1923), adotou a metódica de Bernheim e de Seignobos, dando lugar à emergência da "Nueva Escuela Histórica" argentina (Devoto, 2009, p.124-125). 


\section{CONCLUSÕES}

Ao final dos comentários sobre essas quatro experiências, podemos afirmar, que os missionários apresentaram intenções relativamente divergentes. Todos reconheciam a superioridade das instituições alemãs de ensino superior, quando comparadas à França, Estados Unidos e, ainda mais, em relação à Inglaterra e à Espanha. No entanto, as missões foram promovidas por interesses diferenciados. Adams e Seignobos concluíram seus estudos doutorais na Alemanha. O primeiro interessou-se pela estruturação do gênero história política, em bases científicas e de ideal nacionalista. O segundo foi orientado a colher experiências que auxiliassem a uma provável reforma no ensino superior sob a tutela dos republicanos. Fredericq e Quesada, por sua vez, viajaram explicitamente com o objetivo de conhecer práticas inovadoras. Ocorre que a história e os seminários já eram praticados na Bélgica em moldes antiquários germânicos, enquanto a Argentina, que vivia de preleções, ainda pensava em instituir uma licenciatura em história, com ênfase na abordagem sociológica (nomotética).

Dada a quantidade de espaços onde se edificavam e se instituam os seminários nos estados alemães - residências, associações de estudantes, espaços físicos concedidos pelas faculdades e universidades - , as diferenças de percursos no interior da Alemanha e também das fontes consultadas - observação participante, entrevistas, conversas informais, discursos orais e escritos, leitura de programas, listas de cátedras e relatórios estatísticos etc. - as descrições produzidas pelos viajantes sobre um seminário ideal, inscrito em suas mentes, antes de saírem dos seus países, foram as mais diversas. Seignobos enfatizou a relação jurídico-espacial (cursos públicos vs. cursos em espaço privado). Fredericq importou-se com as dimensões cognitivas ou psicomotoras (cursos teóricos $v s$. cursos práticos). Adams pôs os olhos na função social (formação de professortransmissor $v s$. formação do especialista-pesquisador), o mesmo fazendo o argentino Quesada, com sutil diferença (investigar determinado tema vs. comunicar determinado tema às crianças e adolescentes).

Quanto às implicações das classificações e valorações, obviamente, elas também divergiram. A experiência de Adams foi replicada em 
várias universidades estadunidenses, predominantemente, como instituição física - edifício/laboratório, bem ao modo das ciências naturais, com total apoio e inspiração nas práticas de Bluntschli (Heildelberg). O trabalho de Fredericq reforçou heranças germânicas em curso desde os anos 1870, predominantemente guiado por Conrad (Halle). De Langlois, é bastante conhecida a inclusão de práticas antiquárias no seu Introduction aux études historiques, complementada com as tarefas de agrupamento dos fatos e construção de fórmulas gerais - atividades de síntese, já que a introdução dos exercícios práticos, agrupando uns poucos alunos em torno de um experiente historiador, estava presente na École Normale Superieur e na École Supérieur des Hautes Études, introduzidos por outros professores que estagiaram na Alemanha antes de Seignobos, como Gabriel Monod. Do esforço de Quesada, por fim, as investigações sobre os seminários transformaram-se em um projeto de Instituto histórico de caráter transnacional, ou seja, um conjunto de seminários, conduzidos por um mestre experiente, sob um edifício especialmente construído - muito semelhante ao laboratório estadunidense - , inspirado na experiência de um historiador que navegava contra a corrente dominante (nacional e política) do modo de produzir história na Alemanha: Karl Lamprecht (Leipzig).

Limitados aos depoimentos de Adams, Seignobos, Federicq e Quesada, colhidos no período 1877-1909, podemos afirmar que não havia "o objeto" (no sentido de coisa ou referente) seminário a ser descrito na Alemanha. São "objetos" (significados, no plural) o que vemos pelas lentes dos missionários, realizados e designados em diferentes significações. O próprio étimo é grafado em latim e em alemão e tem o sentido modificado, na própria Alemanha: de instituição formadora de professores primários (repetidores) ou secundários a ambiente de desenvolvimento das habilidades de investigação (descobridores).

Quanto aos modos missionários de designar os seminários, eles também se modificam: seminários ["seminar"], exercícios [“Übung”], exercícios históricos ["Historisches Übung"], dissertação de tópicos ["Kleine Arbteiten”], exame de fontes [“Quellenstudien”] são agora designados "cours", "exercices", "seminary-work training", "cours pratiques d'Histoire" 
e "ejercicios prácticos". Quando relacionados a método, ganham as formas de estratégias para ensinar, método de seminário, seminário de métodos e seminário de seminários de todos os métodos necessários à produção do conhecimento histórico.

A inexistência de um único referente, os diferentes modos de grafar o seminário e também as variadas designações empreendidas aproximam e distanciam missionários e os citados historiadores contemporâneos do seminário. Distanciam porque historiadores do século XX não escrevem sob pressão da demanda de instituir uma formação singular. Na passagem do século XX para o XXI, historiadores já se constituem profissão transnacionalizada. Por isso, a disputa se dá em torno da proveniência e não da validade como traço diacrítico do historiador. Por outro lado, missionários e estudiosos do seminário e do método se igualam quanto à determinação imposta por seus interesses e culturas às suas significações de seminário e método. Em outros termos, eles mantém ou modificam signos e sentidos por razões idênticas às dos missionários: 1. Os tradutores partem de políticas educacionais centralizadas (França e Bélgica) e descentralizadas (EUA e Argentina); 2. não vivenciam o todo multifacetado da Alemanha (22 universidades); 3. observam o que têm interesse de ver aplicado ou modificado no seu país - liberdade pedagógica, unicidade do método crítico, adoção de habilidades de composição, supressão da crítica documental como sentido em si mesma e possibilidade de efetuar generalizações sobre o passado; 4 . transformam o método histórico em objeto dependente do método de ensino (seminário), o seminário em método histórico e, ainda, entendem o seminário como instituição agregadora de todas as variantes da prática. Além disso, (5) definem método a partir da demanda por formação de professores para a escola básica, da natureza da fonte relativa ao domínio de pesquisa do seu interesse em cada local: todas em suporte papel, mediadoras de informações sobre o nacional (EUA e Bélgica) e o nacional/universal (França e Argentina) nos últimos cinco séculos.

Esse conjunto de variáveis e de resultados reforçam a posição de Gabriele Ingelbach que, mesmo partindo de outra abordagem - a conjugação de práticas da história comparada com a análise das transferências de 
estratégias de formação historiadoras "inter-sociais" - chegou a conclusões idênticas: é pouco racional pensar a existência de um "modelo alemão" de disciplina história, dada a diversidade espaço-temporal no referido país e, menos razoável ainda, afirmar sobre a sua transferência para lugares como a França e os EUA (Ingelbach, 2011, p.51).

O que intriga e nos motiva a continuidade das pesquisas é o fato de a ideia de trabalhar com fontes coevas, mediado por técnicas antiquárias e a composição de um relato, sob compromissos éticos, por exemplo, de honestidade e precisão, no relacionamento entre as fontes e a argumentação, serem partilhados por todos os missionários, independentemente das diferenças de experiências e de expectativas aqui descritas. Isso implica dizer que o fenômeno da transnacionalização da identidade profissional historiadora, datável entre 1870 e 1930, é sim uma hipótese com grande chance de permanência para os próximos anos, inclusive no Brasil.

\section{Agradecimentos}

Este texto foi financiado parcialmente com recursos do Edital MCTI/ CNPQ/MEC/CAPES n. 22/2014 - Ciências Humanas, Sociais e Aplicadas.

\section{REFERÊNCIAS BIBLIOGRÁFICAS}

ASSIS, Arthur. Schemes of Historical Method in the Late 19th Century: Cross -References between Langlois e Seignobos, Bernheim and Droysen. 2015. Disponível em: http://www.academia.edu/10150635/Schemes_of_ Historical_Method_in_the_Late_19th_Century_Cross-References_ between_Langlois_and_Seignobos_Bernheim_and_Droysen.

BENTLEY, Michael. Companion to Historiography. London: Routledge, 2007. BLANKE, Horst; FLEISCHER, Dirk; RÜSEN, Jönr. Theory of History in Historical Lectures: The German Tradition of Historik, 1750-1900. History and Theory, vol. 23, n. 3, p.331-356, 1984. 
BOER, Pim den. History as a Profession: The Study of History in France, 1818-1914. Princeton: Princeton University Press, 1998.

BREISACH, Ernest. Historiography Ancient, Medieval, \& Modern. Chicago: The University of Chicago Press, 1994.

BUCHBINDER, Pablo. Qué debe saber un historiador? Reflexiones sobre los modelos curriculares y la enseñanza superior de la historia de la Argentina durante el siglo XX. Clio \& Associados, n. 15, p.157-177, 2011. BUNGE, C. O. A propósito de la reciente publicación de La enseñanza de la historia en las universidades alemanas, por el doctor Ernesto Quesada, Buenos Aires: [sn]. 1911. Disponível em: http:// www.bnm.me.gov.ar; Acesso em: $21 \mathrm{dez} .2015$.

BURKE, Peter. Paradigms Lost - from Göttingen to Berlin. Common Knowledge, vol. 14, n. 2, p.243-257, 2008. Disponível em: http://muse-jhu -edu.ez20.periodicos.capes.gov.br/journals/common_knowledge/v014/ 14.2.article.pdf; Acesso em: 21 jan. 2015.

CHARLE, Cristophe. Vue d'Allemagne. In: CHARLE, Cristophe. La République des universitaires (1870-1940). Paris: Seuil, 1994. p.21-59.

CLARK, William. Academic Charisma and the Origins of the Research University. Chicago: The University Chicago Press, 2006.

CUNNINGHAM, Raymond. The German Historical World of Herbart Baxter Adams: 1874-1876. The Journal of American History, vol. 68, n. 2, p.261-275, sep. 1981.

DEVOTO, Fernando J. A história e as ciências sociais na profissionalização da historiografia argentina. Tempo Social, vol. 21, n. 2, p.109-132, 2009. ESCHENBACHER, Herman. F. Growth of Professional History in America. Peabody Journal of Education, vol. 42, n. 2, p.76-83, sep. 1964.

ESKILDSEN, Kasper Risbjerg. Inventing the Archive: Testimony and Virtue in Modern Historiography. History of the Human Sciences, vol. 26, n. 4, p.8-26, 2013.

ESKILDSEN, Kasper Risbjerg. Leopold von Ranke, la passion de la critique et le séminaire d'histoire. In: JACOB, Christian (org.). Lieux de savoir espaces et communautés. Paris: Albin Michel, 2007. p.462-482. 
FEBVRE, Lucien. Combats pour l'histoire. Paris: Armand Colin, 1952.

FUCHS, Eckhardt. Provincializing Europe: Historiography a Transcultural Concept. In: FUCHS, Eckhardt; STUCHTEY, Benedikt (orgs.). Across Cultural Borders: Historiography in Global Perspective. Maryland: Roman \& Littlefield, 2002. p.01-28.

HARRISON, Robert; JONES, Aled; LAMBERT, Peter. A institucionalização e a organização da história. In: LAMBERT, Peter; SCHOFIELD, Phillipp (coords.). História: introdução ao ensino e à prática. Porto Alegre: Pensa, 2011. p.25-42.

HAUPT, Heinz-Gerhard; KOCKA, Jürgen. Comparative and Transnational Approaches and New Perspectives. New York: Berghahn Books, 2009.

IGGERS, Georg. Historiography in the Twentieth Century: From Scientific Objectivity to the Postmodern Challenge. Hanoveer: Wesleyan University Press, 1997.

INGELBACH, Gabrielle. Intercultural Transfer and Comparative History: The Benefits and Limits of Two Approaches. Traversea, vol. 1, p.46-59, 2011. INGELBACH, Gabrielle. Professional Communication - The Seminar - A Place for Learning and Teaching. In: PORCIANI, Ilaria; RAPHAEL, Lutz. Atlas of European Historiography - The Making of a Profession (18002005). Cambridge: Palgrave Macmillan; European Science Foundation, 2010. p.24.

KEYLOR, William R. Academy and Community: Foundation of the French Historical Profession. Cambridge: Harvard University Press, 1975.

KRUSE, Otto. The Origins of Writing in the Disciplines: Traditions of Seminar Writing and the Humboldtian Ideal of the Research University. Written Communication, vol. 23, n. 3, p.331-352, july 2006.

LE GOFF, Jacques. História e memória. Campinas: Editora da Unicamp, 1992.

MARROU, Henri-Irénée. De la connaissance historique. Paris: Le Seuil, 1954.

OLIVEIRA, Maria Margarida Dias de. Educação e sociedade: quem ensina e quem aprende. Anais da Primeira Jornada de Ensino de História de Pernambuco. Recife: UFPE, 2015. 
PAUL, Herman. The Scholarly Self: Ideals of Intellectual Virtue in NineteenthCentury Leiden. In: BOD, Rens; MAAT, Jaap; WESTSTEIJN, Thijs (orgs.). The Making of the Humanities, vol. 2: From Early Modern to Modern Disciplines. Amsterdam: Amsterdam University Press, 2012. p.397-411. PROST, Antoine. Charles Seignobos revisité. Vingtième Siècle, Revue d'Histoire, vol. 43, n. 1, p.100-118, 1994.

RICHTER, Melvin. Mais que uma via de mão dupla: analisando, traduzindo e comparando os conceitos políticos de outras culturas. In: FERES JÚNIOR, João; JASMIN, Marcelo. História dos conceitos: diálogos transatlânticos. Rio de Janeiro: PUC-RJ; Loyola; IUPERJ, 2007. p.01-29.

SMITH, Bonnie G. Gender and the Practices of Scientific History: The Seminar and Archival Research in the Nineteenth Century. The American Historical Review, n. 100, vol. 4, p.1150-1176, 1995.

SMITH, Bonnie G. The Gender of History: Men, Women and Historical Practice. Cambridge and London: Harvard University Press, 1998.

TELMAN, David Aaron Jeremy. Clio Ascendant: The Historical Profession in Nineteenth-Century Germany. Ithaca, NY: Cornell University, 1993. TORSTENDAHL, Rolf. The Rise and Propagation of Historical Professionalism. New York: Routledge, 2015.

VANNEUVILLE, Rachel. La mise en forme savante des sciences politiques. Les usages de la référence allemande dans l'institutionnalisation de l'Ecole libre des sciences politiques à la fin du XIXe siècle. Politix, vol. 15, n. 59, p.67-88, 2002.

WOOLF, Daniel. Uma história global da história. Petrópolis: Vozes, 2014. 